The Texas Medical Center Library

DigitalCommons@TMC

The University of Texas MD Anderson Cancer Center UTHealth Graduate School of

Biomedical Sciences Dissertations and Theses

(Open Access)
The University of Texas MD Anderson Cancer

Center UTHealth Graduate School of

Biomedical Sciences

\title{
$5-2017$
}

\section{Genesurance Counseling: Patient Perspectives}

\author{
Chelsea Wagner
}

Follow this and additional works at: https://digitalcommons.library.tmc.edu/utgsbs_dissertations

Part of the Medical Genetics Commons

\section{Recommended Citation}

Wagner, Chelsea, "Genesurance Counseling: Patient Perspectives" (2017). The University of Texas MD Anderson Cancer Center UTHealth Graduate School of Biomedical Sciences Dissertations and Theses (Open Access). 759.

https://digitalcommons.library.tmc.edu/utgsbs_dissertations/759

This Thesis (MS) is brought to you for free and open access by the The University of Texas MD Anderson Cancer Center UTHealth Graduate School of Biomedical Sciences at DigitalCommons@TMC. It has been accepted for inclusion in The University of Texas MD Anderson Cancer Center UTHealth Graduate School of Biomedical Sciences Dissertations and Theses (Open Access) by an authorized administrator of DigitalCommons@TMC. For more information, please contact digitalcommons@library.tmc.edu.

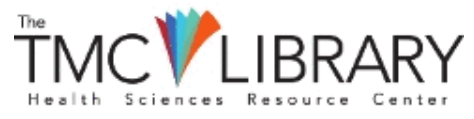




\section{GENESURANCE COUNSELING: PATIENT PERSPECTIVES}

By

Chelsea Alice Wagner, B.S.

\section{APPROVED:}

Jen Hoskovec, MS, CGC

Advisory Professor

Lauren Murphy, MS, CGC

Jacqueline Harkenrider, MS, CGC

Sandra Darilek, MS, CGC

Eleazar Soto-Torres, MD

APPROVED:

Dean, The University of Texas

MD Anderson Cancer Center UTHealth Graduate School of Biomedical Sciences 


\title{
GENESURANCE COUNSELING: PATIENT PERSPECTIVES
}

\author{
A \\ THESIS \\ Presented to the Faculty of \\ The University of Texas \\ MD Anderson Cancer Center UTHealth \\ Graduate School of Biomedical Sciences \\ in Partial Fulfillment \\ of the Requirements \\ for the Degree of \\ MASTER OF SCIENCE
}

By

Chelsea Alice Wagner, Bachelor of Science

Houston, Texas

May 2017 


\section{ACKNOWLEDGEMENTS}

This project reflects the collaboration and effort of many talented individuals without whom I would have not been able to succeed. In particular, I would like to thank my supportive chair, Jennifer Hoskovec, for her invaluable guidance and mentorship. You have encouraged my independence and ownership of this project, and have fostered an immense feeling of pride and accomplishment. Additionally, I would like to extend my heartfelt gratitude to my committee members: Lauren Murphy, Jacqueline Harkenrider, Sandra Darilek, Quinn Stein, Dr. Eleazar Soto-Torres, and Dr. Syed Hashmi, for their instrumental contributions and support throughout this project.

I am extremely grateful to have had the opportunity to train at the University of Texas Genetic Counseling Program under the guidance and support of our fearless leaders Claire Singeltary and Jennifer Czerwinksi. To the countless other supervisors and mentors who have contributed greatly to my education and shaped the genetic counselor I have become, you have my eternal gratitude.

To my family and friends who have provided me with endless support and encouragement, I can never say thank you enough. To my exceptional classmates Jordan Berg, Maggie Clifford, Leslie Durham, Amanda Gerard, Meagan Kaulfus, Katy Reese, and Ellen Zirklebach: I couldn't imagine doing this with anyone else. To my wonderful parents who always encouraged me to follow my dreams, even when they take me far from home: thank you. To my brilliant sister who taught me what it means to be a fierce, independent, and intelligent woman: thank you. Finally, to my supportive husband: thank you for being my biggest fan and always being up for an adventure, especially the one called grad school. 


\title{
GENESURANCE COUNSELING: PATIENT PERSPECTIVES
}

\author{
Chelsea Alice Wagner, B.S.
}

\section{Advisory Professor: Jennifer Hoskovec, M.S., CGC}

Genetic counselors (GCs) have recently reported an increase in the discussion of insurance-related, or "genesurance," topics during genetic counseling sessions. Despite increasing frequency, little knowledge exists about genesurance conversations and patient expectations. This study aimed to assess patient expectations of GCs in genesurance discussions and evaluate if health insurance literacy impacted these expectations. A 38-item survey, including a validated tool to assess health insurance literacy (HIL) was administered prior to patients receiving prenatal or cancer genetic counseling at three participating institutions. A total of 360 responses were analyzed. Key variables were compared using chi-square analysis and multivariable logistic regression was used to assess associations between factors, while controlling for potential confounders. Over $80 \%$ of patients expected genesurance topics to be discussed during a genetic counseling session with a majority expecting their GC to: provide them an estimated out-of-pocket (OOP) cost for a genetic test (83\%), know if a genetic test is a covered benefit (82\%), and provide referral information if they have additional questions (81\%). In general, HIL did not impact patient expectations of GCs. This study provides evidence that patients expect their GCs to be discussing genesurance topics and further delineates their specific expectations. Further studies will be help to establish the most effective way to communicate this information to patients, evaluate current genetic counseling training programs, and assist in the development of further specialized Health Insurance Literacy assessment tools. 


\section{TABLE OF CONTENTS}

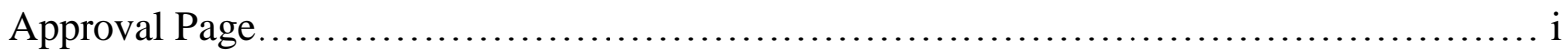

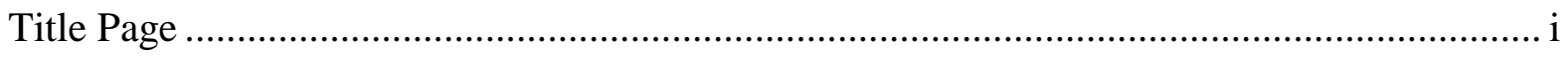

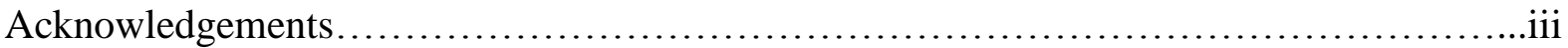

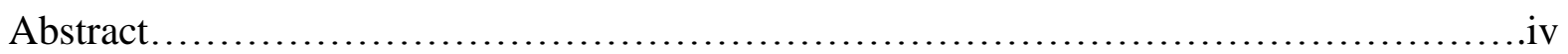

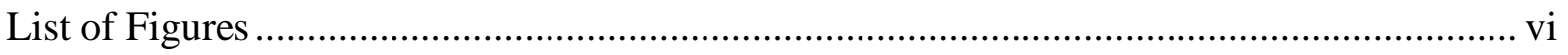

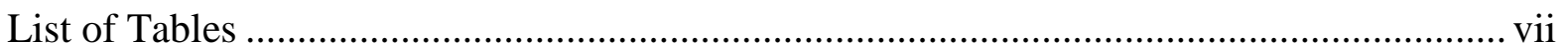

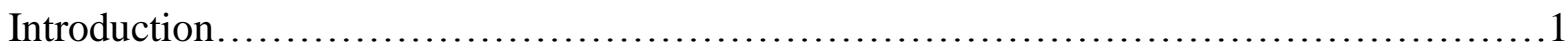

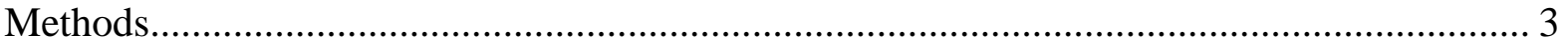

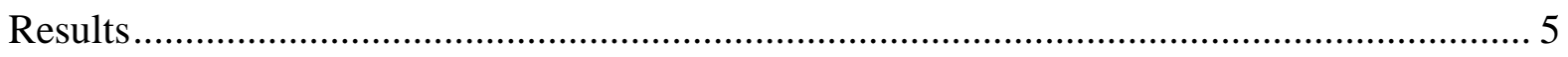

Figure 1: Survey Collection Site Schematic ........................................................ 3

Figure 2: Patient Expectations of Geentic Counselors …....................................... 8

Figure 3: Responsible Parties in Genesurance Discussions........................................... 9

Figure 4: Overall Health Insurance Literacy (HIL) Among All Participants .................... 10

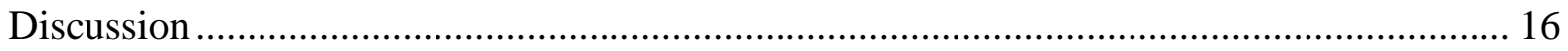

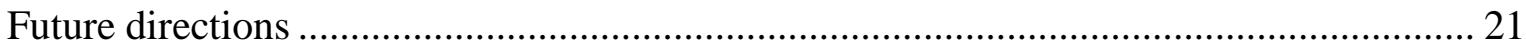

Limitations and Conclusions .......................................................................... 22

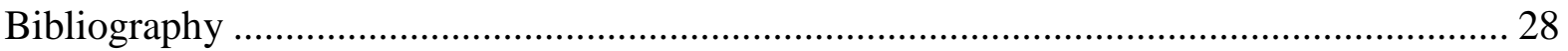

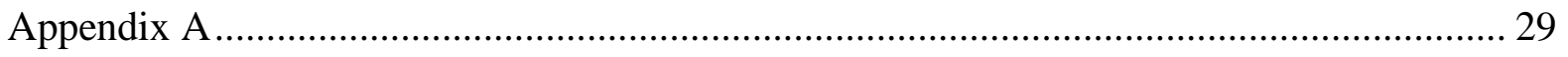

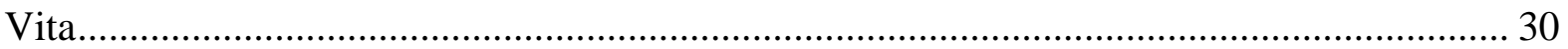




\section{LIST OF FIGURES}

Figure 1: Survey Collection Site Schematic...................................... 3

Figure 2: Patient Expectations of Genetic Counselors..................................

Figure 3: Responsible Parties in Genesurance Discussions........................... 9

Figure 4: Overall Health Insurance Literacy (HIL) Among All Participants .............. 10 


\section{LIST OF TABLES}

Table 1: Participant Demographics.............................................6-7

Table 2: Chi-square analysis of demographic factors and patient expectations of genetic counselors..................................................................... 9

Table 3: Multivariate logistic regression assessing predictors of patient expectations of genetic

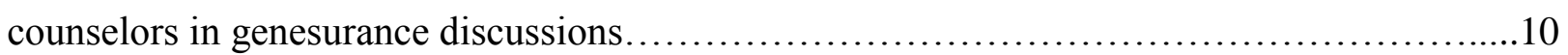

Table 4: Multivariate logistic regression analysis assessing predictors of overall confidence and

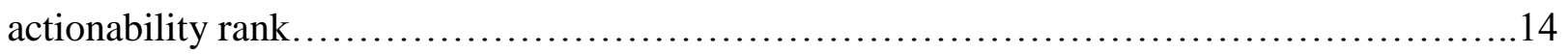

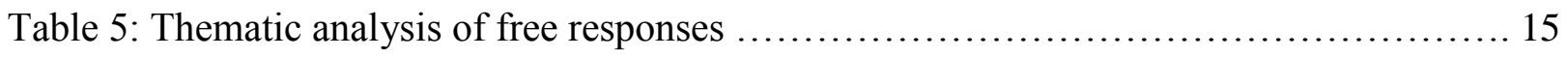




\section{BACKGROUND}

Discussions about potential costs of diagnostic tests, prescriptions and treatment options are often uncomfortable and awkward for healthcare providers to have with patients. The absence of these conversations during the decision making process has been attributed to insufficient provider training and time limitations (Alexander, Casalino, \& Meltzer, 2003; Riggs \& Ubel, 2014) and may have negative effects like "financial toxicity", or increased financial burden for patients resulting in consequences to their health and well-being (Ubel, Abernethy, \& Zafar, 2013; Zafar et al., 2013). With the acknowledgement of the importance of these conversations and patient's desires to have them, it is critical that healthcare providers begin to understand patient expectations in discussing health-care costs (Patel \& Wheeler, 2014; Ubel et al., 2013)

With increasing frequency, genetic counselors across a wide variety of specialties find themselves discussing insurance coverage of genetic testing during genetic counseling sessions (Brown, 2017). These discussions have been termed "genesurance counseling," defined as the portion of genetic counseling that is devoted to the topic of costs and insurance coverage of genetic testing. While recent research has shown that these conversations are taking place more frequently than in the past (Brown, 2017) to our knowledge, there have been no studies examining patient expectations of genetic counselors in these types of discussions.

It is well described that many factors influence patient decision-making in a healthcare setting, including cultural beliefs, socioeconomic status, and patient expectations (Long \& Goin, 2014). These factors, and others, may also affect an individual's comprehension of basic health insurance terms (Long \& Goin, 2014) (Blumberg, Long, 
Kenney, \& Goin). An individual's lack of understanding and familiarity with health insurance coverage can result in under utilization of health care services and poorer overall health (Morgan et al., 2008).

Health insurance literacy is an extension of general health literacy that requires individuals to understand how health insurance benefits are structured and to understand and estimate cost sharing responsibilities (Paez et al., 2014). Health insurance literacy has been defined as "the degree to which individuals have the knowledge, ability, and confidence to find and evaluate information about health plans, select the best plan for their own —or their families'-financial and health circumstances, and use the plan once enrolled" (Quincy, 2012).

In recent years, several tools have been developed to assess health insurance literacy. The American Institute of Research (AIR) created the Health Insurance Literacy Measure (HILM) based on conceptual framework developed at the Health Insurance Literacy Expert Round Table in 2012. This tool was later validated in the national 2013 Health Insurance Literacy Survey as a self-assessment tool that was statistically positively correlated with objective insurance-related knowledge and skills (Paez et al., 2014).

This study aims to explore patient expectations of genetic counselors in genesurance discussions during a genetic counseling session, as well as factors that may impact those expectations, including health insurance literacy. By examining this relationship, we hope to further define the role of a genetic counselor in these genesurance discussions, assess the need for further insurance-related training within genetic counseling training programs, and highlight areas for future research. 


\section{METHODS}

\section{Recruitment}

From August 22, 2016 through January 27th, 2017, individuals who were at least 18 years old, English speaking, and receiving cancer or prenatal genetic counseling were invited to participate in the study. Participating centers were staffed by prenatal and cancer genetic counselors at UTHealth and Baylor College of Medicine in Houston Texas, and Sanford Health Center in Sioux Falls, South Dakota, Bemidji, Minnesota, and Bismarck and Fargo, North Dakota. This study was approved by the Institutional Review Boards: UTHealth (HSC-MS-16-0427), Baylor College of Medicine (ESP1:H-39706), and Sanford-Augustana Health System (STUDY00000799).

Survey

Patients willing to participate completed a paper survey prior to receiving genetic counseling. De-identified responses from the survey were collected and recorded in a secure electronic database. The survey consisted of four sections; demographics, a validated Health Insurance Literacy Measurement tool (HILM), assessment of patient expectations of genetic counselors in genesurance discussion, and a free response opportunity, totaling 38 questions.

The survey was developed by investigators based on anecdotal clinical experience and published literature (Brown, 2017). Questions were designed to specifically assess (1) patient expectations of genetic counselors in terms of the content and depth of genesurance discussions; (2) how long and when these conversations should take place during a genetic counseling session; (3) patient expectations of genesurance discussions in other health care settings (i.e. outside of genetic counseling) and; (4) who is responsible for initiating genesurance discussions. For the purpose of this study, we define the term "genesurance 
counseling" as the portion of the genetic counseling session, whether intentional or unintentional, that is devoted to the topic of costs and third party coverage of genetic testing.

\section{Ranking Health Insurance Literacy Among Participants}

This study assessed patient's health insurance literacy using the HILM and the impact of this factor upon patient's expectations of genesurance discussions by genetic counselors. The HILM was subdivided into two separate scales: a confidence scale and likelihood of performing certain actions scale, deemed "actionability" for the purposes of this study, when using health insurance (Paez et al., 2014).

Individuals who completed the Health Insurance Literacy Measure (HILM) portion of the survey were given an overall weighted score for confidence and actionability. The weighted score was calculated by assigning point values to each possible answer $(1 \mathrm{pt} .=$ not

at all, 2 pt. $=$ somewhat, 3 pt. $=$ moderately, 4 pt. $=$ very), summing those points, and dividing by the total points possible in the measure. This was then used to rank participants into categories of overall high, moderate, low, and no confidence and actionability scores.

\section{Statistical Analysis}

Data were analyzed using data analysis and statistical software STATE v.13. Descriptive statistics were calculated for all variables using means and standard deviations for continuous variables and frequency and percent for categorical responses. Chi-square tests were performed to analyze differences between groups and categorical variables. Statistical significance was assumed at Type I error rate of 5\%. Multivariate logistic regression was used to assess associations between key factors, while controlling for potential confounders. 


\section{RESULTS}

A total of 365 patients took part in this survey across all participating institutions

(Figure 1). Responses from participants who only completed the demographic section were eliminated, leaving 358 responses for analysis. Not all respondents completed the survey in its entirety, resulting in lower response rates for some questions.

\section{Figure 1: Survey Collection Site Schematic}

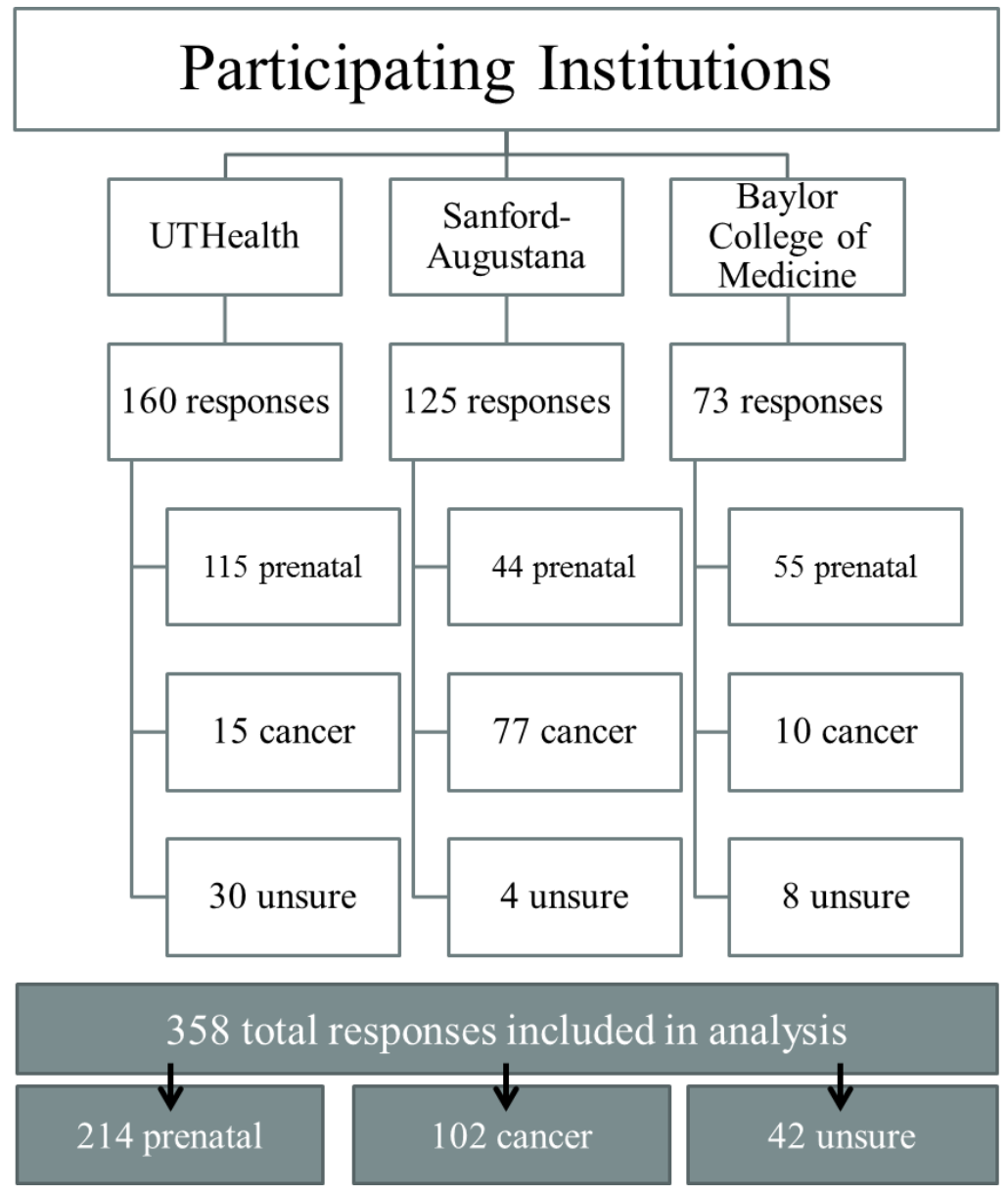

The mean age of the study population was 36 years old. The majority $(59.8 \%)$ of participants were receiving prenatal genetic counseling, while $28.5 \%$ were receiving cancer genetic counseling, and $11.7 \%$ of participants were unsure about which type of genetic counseling they would be receiving. Participants from the UTHealth system represented 
44.5\% of respondents $(n=164)$, while participants from the Sanford Health system represented $34.7 \%$ of respondents $(n=136)$, and participants from the Baylor College of Medicine system represented $20.8 \%$ of respondents $(n=75)$. Most participants identified as Caucasian $(58.3 \%)$ or Hispanic (19.7\%) and reported having private insurance $(73.5 \%)$

(Table 1).

Table 1: Participant Demographics

\begin{tabular}{|l|ll|}
\hline Type of Genetic Counseling $(n=358)$ & $n$ & $(\%)$ \\
\hline Prenatal Genetic Counseling & 214 & 59.8 \\
Cancer Genetic Counseling & 102 & 28.5 \\
Unsure & 42 & 11.7 \\
\hline Location of Genetic Counseling $(n=358)$ & $n$ & $(\%)$ \\
\hline UTHealth System, Houston, TX & 160 & 44.7 \\
Baylor College of Medicine, Houston, TX & 73 & 20.4 \\
Sanford Health System ND, MN, SD & 125 & 34.9 \\
\hline Age $(n=350)$ & $n$ & $(\%)$ \\
\hline 18-24 & 32 & 9.1 \\
25-34 & 153 & 43.7 \\
35-44 & 106 & 30.3 \\
45-54 & 27 & 7.7 \\
55+ & 32 & 9.1 \\
\hline Ethnicity $(n=355)$ & $n$ & $(\%)$ \\
\hline Caucasian/White & 207 & 58.3 \\
Hispanic/Latino & 70 & 19.7 \\
Black/African American & 42 & 11.8 \\
Native American & 4 & 1.1 \\
Asian/Pacific Islander & 21 & 5.9 \\
Other/Bi-racial & 11 & 3.1 \\
\hline Type of Insurance $(n=358)$ & $n$ & $(\%)$ \\
\hline Private Insurance & 263 & 73.5 \\
Public Insurance & 88 & 24.6 \\
Other & 4 & 1.1 \\
I'm not sure & 3 & 0.8 \\
\hline
\end{tabular}




\begin{tabular}{|l|ll|}
\hline Obtaining Coverage $(n=357)$ & $n$ & $(\%)$ \\
\hline Purchased personally & 22 & 6.2 \\
Covered under spouse's insurance & 85 & 23.8 \\
Received coverage through job & 154 & 43.1 \\
Applied for government/public programs & 86 & 24.1 \\
Other & 10 & 2.8 \\
\hline Born in the United States $(n=359)$ & $n$ & $(\%)$ \\
\hline Yes & 304 & 84.7 \\
No & 55 & 15.3 \\
\hline Annual Household Income $(n=353)$ & $n$ & $(\%)$ \\
\hline$<\$ 24,000$ & 66 & 18.7 \\
$\$ 25,000-\$ 49,999$ & 53 & 15.0 \\
$\$ 50,000-\$ 100,000$ & 102 & 28.9 \\
$>\$ 100,000$ & 93 & 26.4 \\
Prefer not to answer & 39 & 11.1 \\
\hline
\end{tabular}

\section{Patient Expectations of Genetic Counselors}

Overall, $80 \%$ of patients expect their genetic counselor to discuss genesurance related topics during a genetic counseling session. Within those discussions, the majority of individuals expect their genetic counselor to know if a test or procedure is a covered benefit (82.1\%), provide an estimated out-of-pocket cost (83.0\%), and provide contact or referral information if they have additional genesurance-related questions (81.2\%). Other expectations included genetic counselors providing information regarding cost and coverage specific to each individual's insurance plan (61.0\%), and providing an exact out-of-pocket cost for genetic tests (43.4\%) (Figure 2). 
Figure 2: Patient Expectations of Genetic Counselors

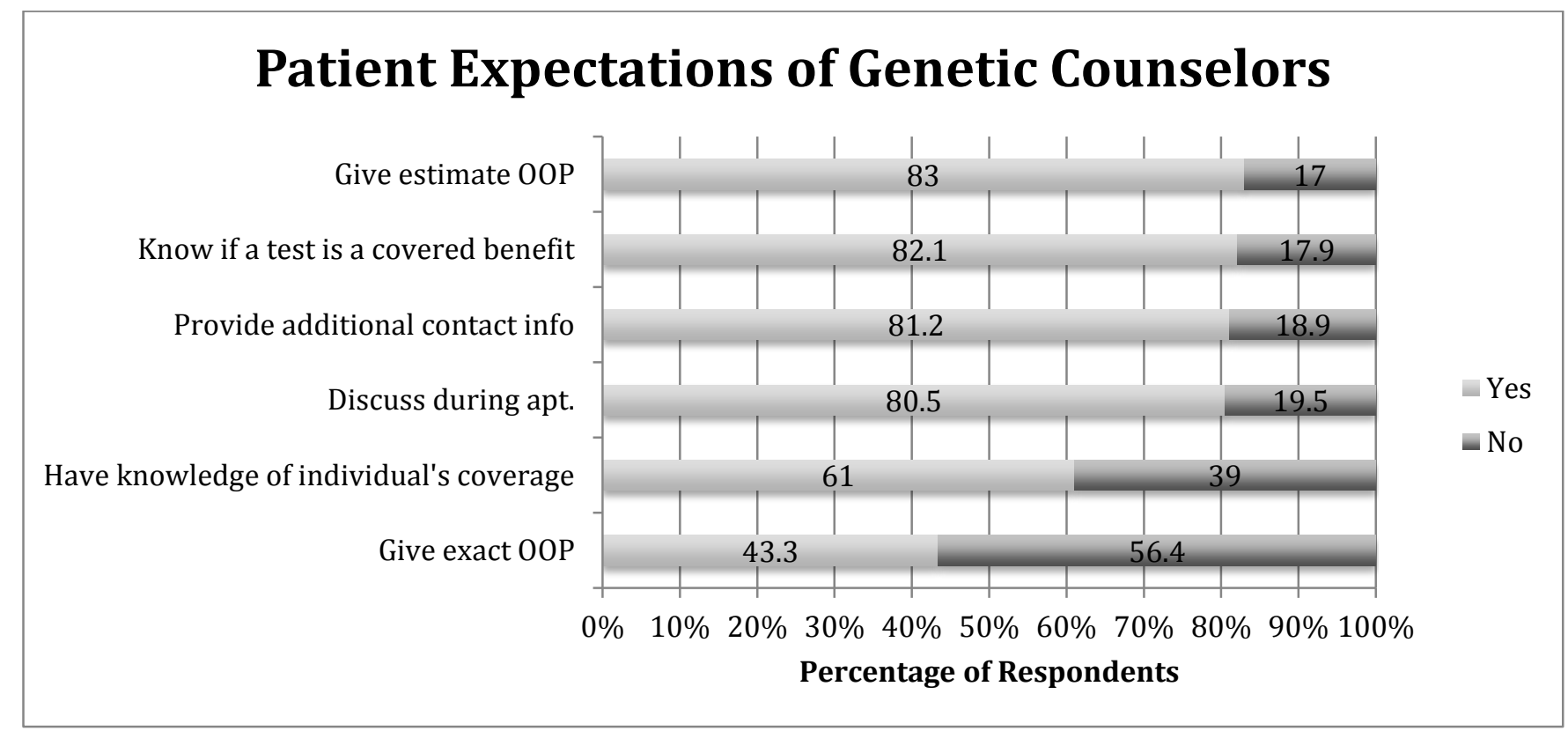

Various factors were significantly associated with patient expectations of genetic counselors (Table 2). However, many of the factors (e.g. type of insurance and how respondents obtain insurance) are associated with each other. Therefore, secondary analyses using multivariable logistic models were performed to assess for effect modification or confounding. These models demonstrated that ethnicity was the major independent predictor of patient expectations of a genetic counselor providing information based off of an individual's insurance plan and coverage, and providing an exact out-of-pocket cost (Table 3). The other expectations were not influenced by a single predominant factor. 


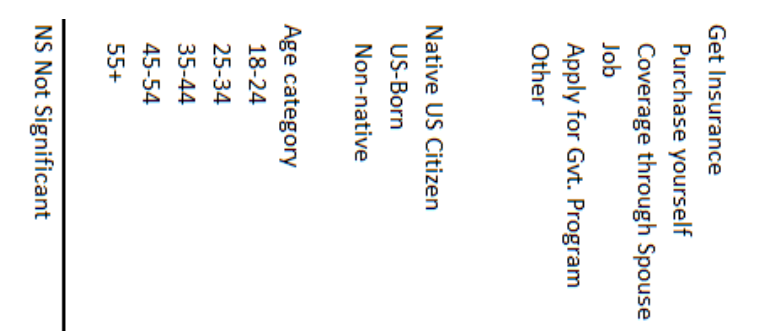

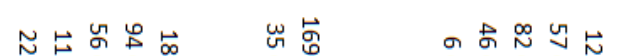

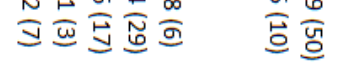

$\infty$

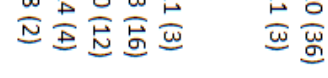

z

$$
\text { 울 }
$$

$\infty \sim \underset{\omega}{\infty} \sim$

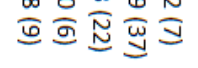

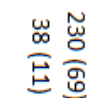

$\stackrel{N}{\underline{N}} \frac{N}{\underline{N}} \frac{\infty}{\underline{D}} \frac{a}{N}$

z

$z$

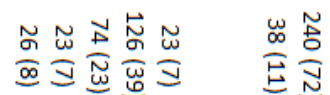

E)

$$
\text { z }
$$

$$
\text { z }
$$

虫

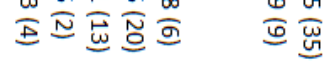

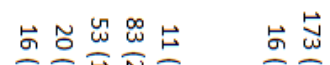

जิ 家芯

웅

웅

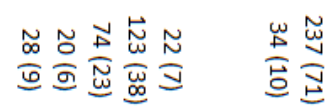

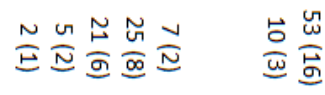

z

$$
\text { z }
$$

N

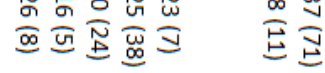

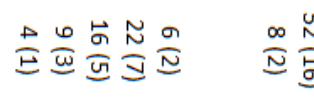

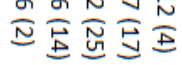

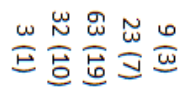

z

$\frac{\sigma}{\omega} \frac{N_{N}}{N} \frac{\vec{N}}{\omega} \frac{N}{N}$

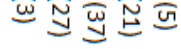

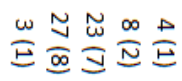

웅

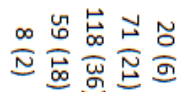

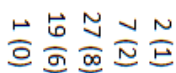

z

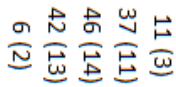

w

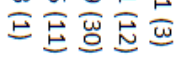

웅

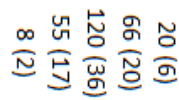

$\mapsto \tilde{\omega} N$

으보ㅇㅛㅛ

z

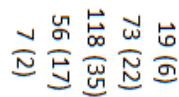

NㅗN $\frac{N}{N} \mathbb{N}$

온

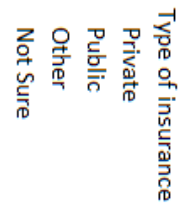

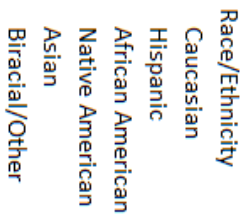

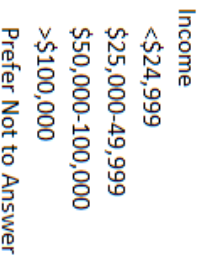

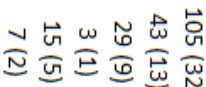

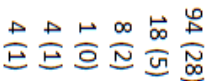

옹

岂

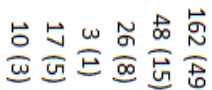

을 $\stackrel{\sim}{\tilde{\omega}} \stackrel{w}{\underline{\infty}}$

옹

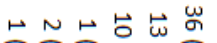

으으톹

in

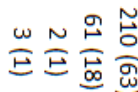

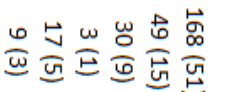

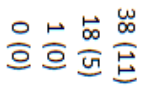

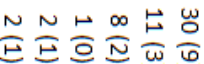

$$
\text { z }
$$

z

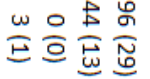

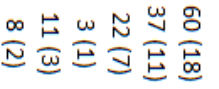

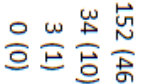

웅

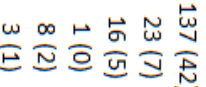

웅

EN

우술

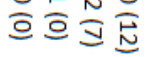

z

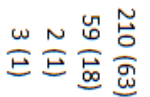

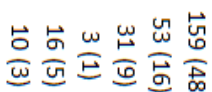

○ N N

으토욜

$\mapsto \omega \mapsto \sigma \infty$ t

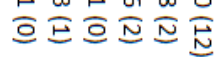

ำ งั $\stackrel{\infty}{\omega}$ $\omega$

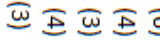

官

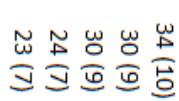
占 토으응

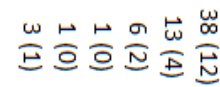

z

웅

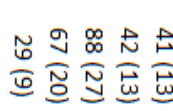

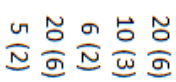

ஓे

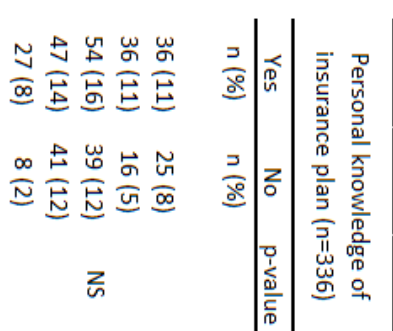

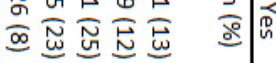

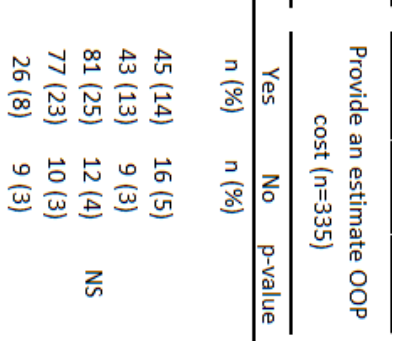

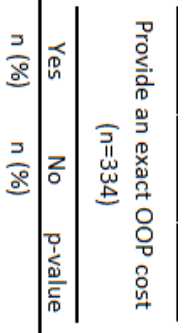

z

z 


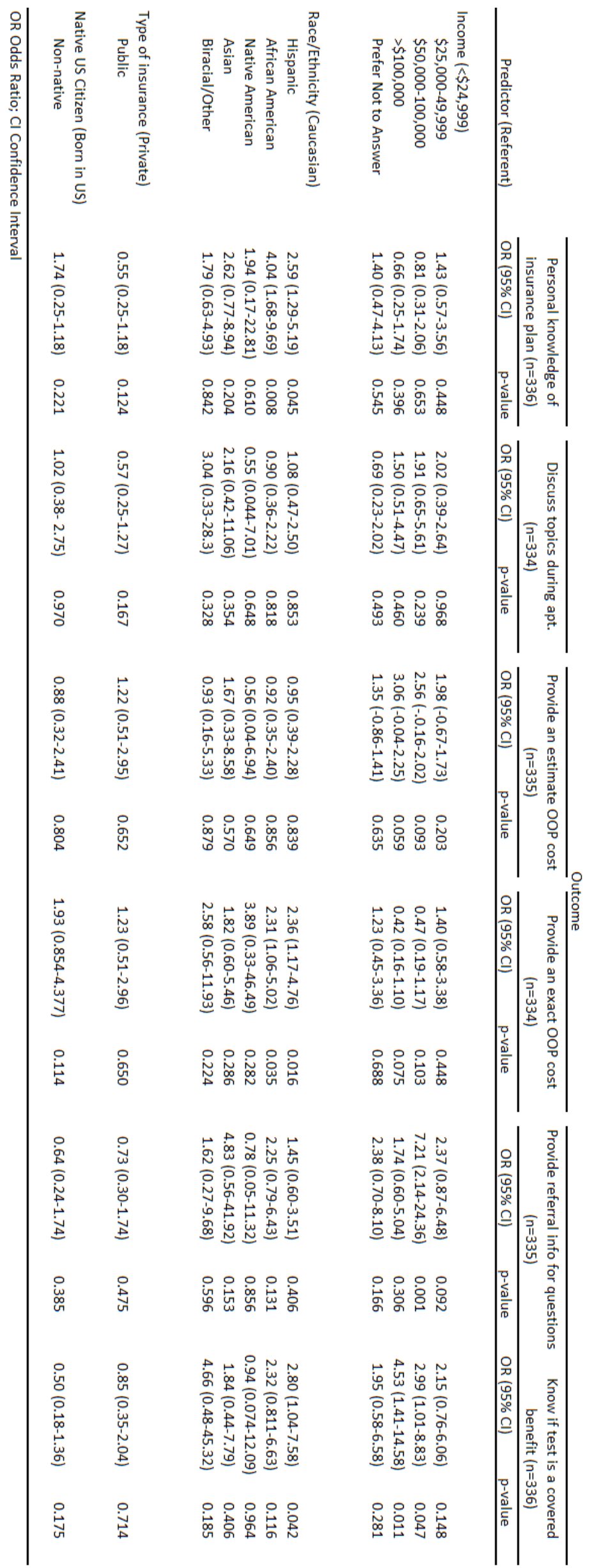


For these two expectations, ethnicity was the only significant predictor of response. Hispanics were 2.59 times more likely to expect personalized insurance information from their genetic counselor than Caucasians $(\mathrm{p}=.045)$. While African Americans were 4.04 times more likely to expect this specific information from their counselors than Caucasians $(\mathrm{p}=.008)$. In regards to expecting an exact out-of-pocket cost, Hispanics were 2.31 times more likely to expect this than Caucasians ( $\mathrm{p}=.016)$, while African Americans were 2.36 times more likely to expect this than Caucasians $(\mathrm{p}=.035)$.

Additionally, the type of genetic counseling patients were receiving impacted their expectation of being provided an exact out-of-pocket cost. Individuals receiving prenatal counseling were 1.75 times more likely to expect an exact out of pocket cost than individuals receiving cancer counseling $(p=.031)$.

\section{Impact, Length, and Timing}

Over $67 \%$ of respondents believe that genesurance discussions can alter their decision-making process and ultimately impact whether or not they pursue genetic testing. Almost $79 \%$ of patients would like genesurance discussions to take place before they make a decision about pursuing genetic testing. Only $9 \%$ of patients preferred these discussions to take place after they make a decision regarding testing, another $9 \%$ of patients only wanted to discuss these topics when they brought them up themselves. In terms of the length of genesurance conversations, $30 \%$ of patients wanted to spend less than five minutes discussing these topics, $38 \%$ wanted to spend 5-10 minutes, while $26 \%$ wanted to discuss these topics until they had no more questions.

\section{Responsible Parties}


Over $90 \%$ of patients feel a personal responsibility to ask genesurance related questions in a genetic counseling session. When given the option to select all individuals they felt were responsible for genesurance discussions from a list that included: genetic counselors, physicians, representatives from the insurance company, diagnostic laboratory, provider's billing office, administrative support personnel, and themselves, respondents chose an average of two individuals (Figure 3). Of the 805 selections, the most frequent response was genetic counselor $(n=185)$ followed by personal responsibility $(n=142)$. The least frequent responses were administrative personnel $(n=86)$ and diagnostic laboratory $(n=28)$.

\section{Figure 3: Responsible Parties in Genesurance Discussions}

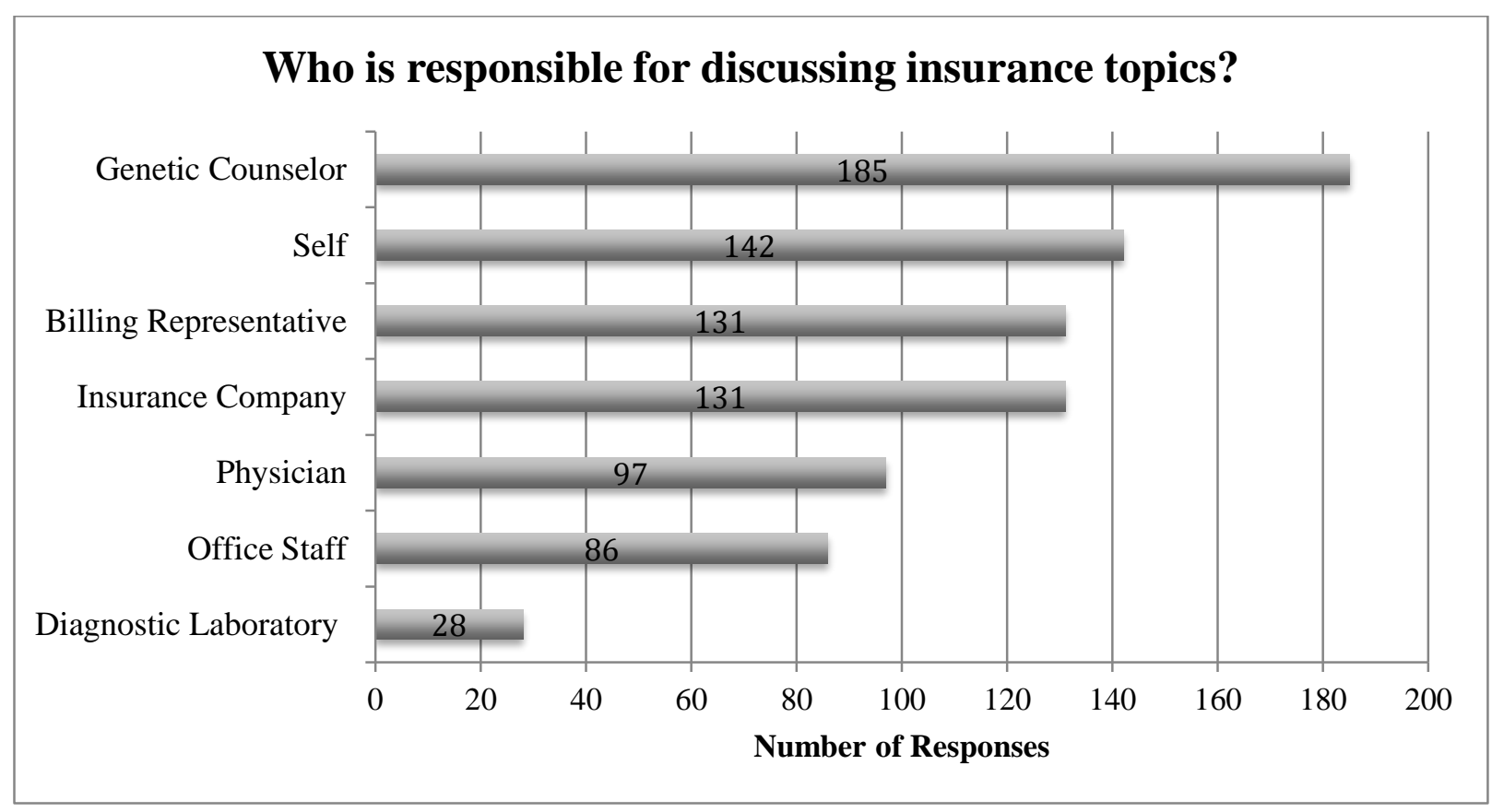

\section{Patient Expectations of Healthcare Providers in Other Settings}

When reflecting on their interactions with primary-care providers, $37 \%$ of patients expected insurance coverage to be discussed at every visit, $26 \%$ of patients expected these conversations only under certain circumstances such as blood work, imaging studies, or 
procedures, while $25 \%$ of patients did not expect these conversations to take place at all with primary care providers. Of note, $10 \%$ of respondents reported that they had not considered insurance coverage discussions in their conversations with primary-care providers before taking this survey.

\section{Health Insurance Literacy}

Participants were ranked into overall confidence groups and actionability groups based on their weighted responses to their respective Health Insurance Literacy Measures. In terms of confidence, approximately $63 \%$ of respondents fell into the low or no confidence groups, while almost $37 \%$ of respondents fell into the moderate or high confidence groups. Over $80 \%$ of respondents fell into the high or moderate actionability groups, while almost $20 \%$ fell into the low or no actionability groups (Figure 4).

Figure 4: Overall Health Insurance Literacy (HIL) Rankings Among All Participants
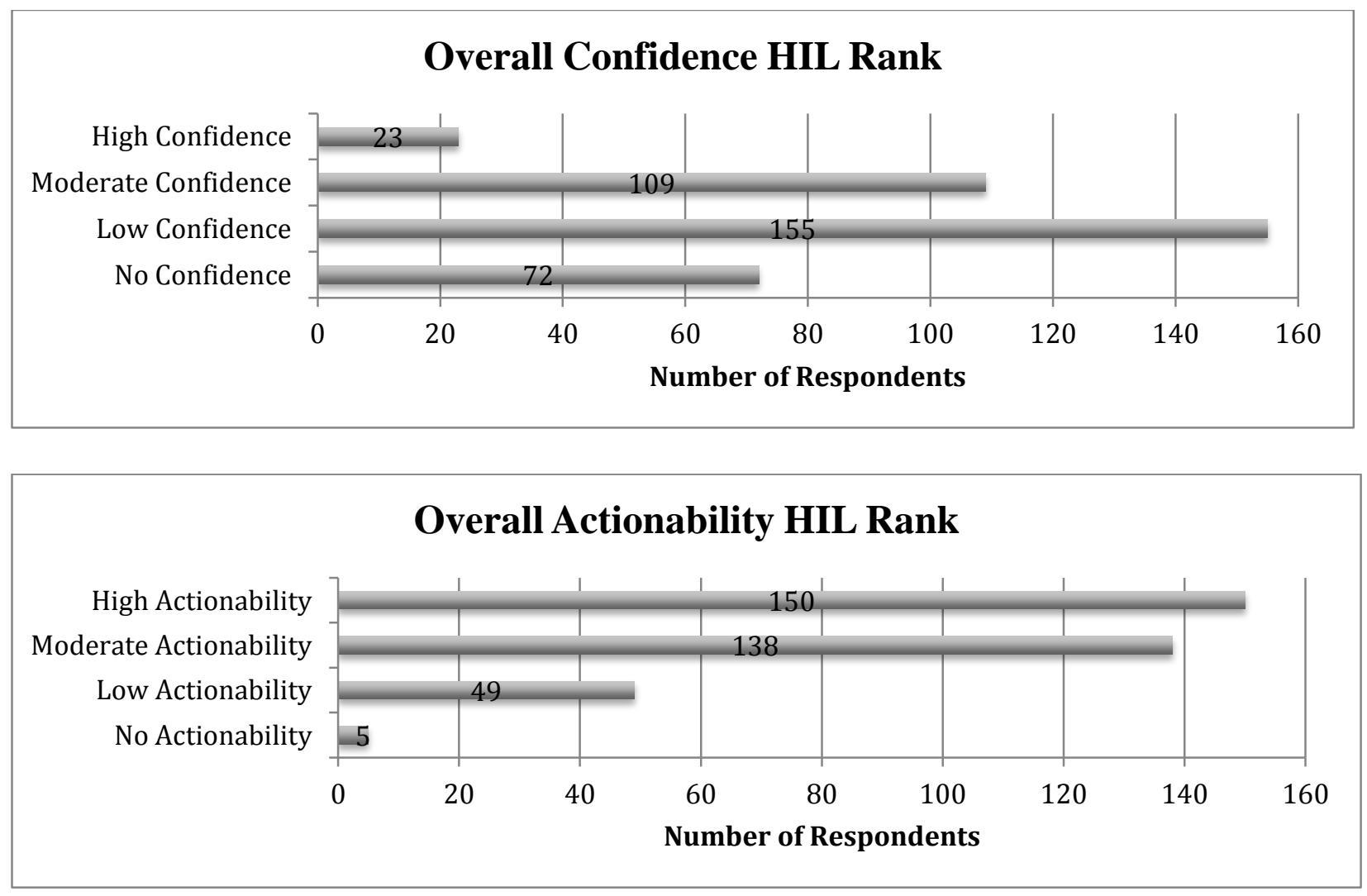
Ordinal logistic regression analysis was conducted to predict confidence and actionability scores using age, ethnicity, income, country of birth, and type of insurance as predictors. Income was the only significant predictor of overall confidence rank amongst all participants. As income increases, the overall confidence level increases. Using the same approach, ethnicity and being born in the United States were significant factors that influenced the overall actionability rank among all participants. Individuals not born in the US, as well as Native Americans were less likely to receive a high actionability score. Individuals who fell into the "low" and "moderate" actionability categories were more likely to feel a personal responsibility to ask genesurance related questions than individuals in the "no actionability" category (Table 4).

\section{Table 4: Multivariate logistic regression analysis assessing predictors of overall}

\section{confidence and actionability rank.}

\begin{tabular}{|c|c|c|c|c|}
\hline \multirow[b]{3}{*}{ Predictor (Referent) } & \multicolumn{4}{|c|}{ Outcome } \\
\hline & \multicolumn{2}{|c|}{$\begin{array}{l}\text { Overall Confidence Rank } \\
\qquad(\mathrm{n}=359)\end{array}$} & \multicolumn{2}{|c|}{$\begin{array}{l}\text { Overall Actionability Rank } \\
\qquad(\mathrm{n}=342)\end{array}$} \\
\hline & OR $(95 \% \mathrm{Cl})$ & $p$-value & OR $(95 \% \mathrm{Cl})$ & $p$-value \\
\hline \multicolumn{5}{|l|}{ Income $(<\$ 24,999)$} \\
\hline$\$ 25,000-49,999$ & $2.06(0.96-4.41)$ & 0.063 & $1.20(0.55-2.64)$ & 0.649 \\
\hline$\$ 50,000-100,000$ & $2.39(1.10-5.20)$ & 0.029 & $1.21(0.53-2.76)$ & 0.655 \\
\hline$>\$ 100,000$ & $4.15(1.81-9.51)$ & 0.001 & $1.40(0.60-3.30)$ & 0.448 \\
\hline Prefer Not to Answer & $1.29(0.54-3.09)$ & 0.569 & $0.51(-.20-1.29)$ & 0.155 \\
\hline \multicolumn{5}{|l|}{ Race/Ethnicity (Caucasian) } \\
\hline Hispanic & $1.14(0.62-2.08)$ & 0.679 & $0.72(0.38-1.37)$ & 0.318 \\
\hline African American & $1.65(0.83-3.30)$ & 0.156 & $1.75(0.84-3.64)$ & 0.137 \\
\hline Native American & $2.72(0.41-17.90)$ & 0.298 & $0.10(0.01-0.78)$ & 0.028 \\
\hline Asian & $1.12(0.46-2.78)$ & 0.794 & $2.06(0.78-5.44)$ & 0.144 \\
\hline Biracial/Other & $2.09(0.51-8.58)$ & 0.305 & $3.91(0.76-20.08)$ & 0.102 \\
\hline \multicolumn{5}{|l|}{ Type of insurance (Private) } \\
\hline Public & $0.98(0.53-1.81)$ & 0.942 & $0.67(0.35-1.29)$ & 0.231 \\
\hline \multicolumn{5}{|l|}{ Native US Citizen (Born in US) } \\
\hline Non-native & $0.59(0.31-1.14)$ & 0.117 & $0.39(0.19-0.77)$ & 0.007 \\
\hline
\end{tabular}




\section{Free Response}

Of the 360 surveys analyzed, 166 participants responded to the free response question which asked how health care providers, including genetic counselors, could best help patients understand their health insurance information. When reviewing these results 8 main themes emerged among the responses including lack of familiarity, provider knowledge, desire to have a conversation, coverage and cost of procedures by insurance, responsible parties, timing of the conversation, impact on decision making, and having tangible resources for reference outside of the appointment. The free responses covered a broad range of expectations, suggestions, and feelings (Table 5). Due to the volume of responses, further analysis was outside the scope of this study.

\section{Table 5: Thematic analysis of free responses}

\begin{tabular}{|c|c|}
\hline Themes & Participant Responses \\
\hline Lack of Familarity & "I have never thought about genetic testing before, so [I] never thought if insurance would cover or not." \\
\hline Provider Knowledge & $\begin{array}{l}\text { "By knowing which tests are broadly covered by most (major, private) insurance companies, then by } \\
\text { advising the patient of their expected OOP expenses." }\end{array}$ \\
\hline Desire to Have a Conversation & "There needs to be a discussion... whether through the counselor, the doctor, or a billing person." \\
\hline Coverage and Cost & "Be familiar with cost/estimate or give information about where to easily get the info elsewhere. \\
\hline \multirow{6}{*}{ Responsible Parties } & Personal Responsibility \\
\hline & $\begin{array}{l}\text { "My [provider] doesn't know the plan coverage I have and it's my responsibility to find out by calling the } \\
\text { insurance company to find out if a procedure or testing is covered." }\end{array}$ \\
\hline & Provider Responsibility \\
\hline & $\begin{array}{c}\text { "I believe any [provider] should advise patients to contact their insurance provider to discuss coverage, as } \\
\text { some tests may or may not be covered." }\end{array}$ \\
\hline & Shared Responsibility \\
\hline & $\begin{array}{l}\text { "I believe I should ask questions about my coverage, but at the same time this is all new to me and it is a } \\
\text { lot of information to take in." }\end{array}$ \\
\hline Timing of the Conversation & "Give a rough estimate prior to testing in order for the patient to make a decision." \\
\hline Impact on Decision Making & "Have a discussion - it's a factor in the decision." \\
\hline Tangible Resources & "Talk about it with everyone, visual aids \& explanations are always helpful." \\
\hline
\end{tabular}




\section{DISCUSSION}

In 2017, Brown et al. reported that a majority of genetic counselors incorporate and recognize the importance of insurance-related counseling as an aspect of their clinical practices. With this in mind, we conducted what we believe to be the first investigational study exploring patient expectations of genetic counselors in these discussions. We also assessed the impact of health insurance literacy on these discussions.

The results of this study demonstrate that more than $80 \%$ of patients expect their genetic counselor to address genesurance related topics during their prenatal or cancer genetic counseling session. When expectations were further delineated, patients expect: an estimated out of pocket (OOP) cost, knowledge if a test or procedure is a covered benefit, and referral information if they have additional questions after these discussions. These expectations fall within a realm of feasibility depending on the time allotted for the genetic counseling visit.

In both prenatal and cancer genetics settings, commonly offered tests such as cell-free DNA screening or pan-cancer panels may have readily accessible list prices through diagnostic laboratory websites or company representatives. In addition, some diagnostic laboratories have billing support or online tools aimed at providing estimated OOP costs based on the patient's insurance information. Others have billing processes in place that allow them to contact the patient if their OOP cost is over a certain amount, giving the patient the opportunity to proceed, decline, or choose a self-pay option. By familiarizing themselves with these billing policies, tools and list prices, genetic counselors may feel better equipped to provide this information as a point of reference to patients, addressing their expectations regarding OOP cost estimates. 
In terms of covered benefits, many insurance companies use national guidelines from professional societies (i.e. NCCN, ACOG, NSGC and ACMG), to help inform testing criteria and determine coverage. These guidelines and clinical judgment can both be used to provide guidance as to whether a genetic test would likely be a covered benefit for an individual patient. In some situations, genetic counselors may not be able to fully answer patient questions regarding insurance-related topics. In this case, providing contact information for the diagnostic laboratory or for a billing representative or staff member who can further address these questions is appropriate.

A substantial number of respondents had additional less-realistic expectations of genetic counselors in genesurance discussions, including genetic counselors having personal knowledge of their insurance plan and coverage (61.0\%) and being provided an exact OOP cost (43.4\%). Given the number of unique insurance companies and plans, genetic counselors would never be able to have personal and specific knowledge of each patient's plan. Furthermore, providing an exact OOP cost is not feasible for any medical provider, given the nuances within each individual's plan (i.e. deductibles, co-pays, etc.) as well as the specifics regarding contracts between insurance companies and diagnostic testing laboratories.

The proportion of patients who expect this depth of knowledge is concerning and may highlight a fundamental misunderstanding of health insurance, specialized testing, and the third party payor system. Importantly, these idealistic expectations can have implications for the counseling session, as it can extend time spent with the patient without providing the expected depth of information and may affect patient's overall satisfaction with the session. 
Interestingly, ethnicity was the only significant demographic predictor of these two expectations. Compared to Caucasians, both Hispanics and African Americans were more likely to expect these two actions from their genetic counselors. It is well documented that individuals in these ethnic groups are less likely to utilize healthcare services (Blumberg et al.; Long \& Goin, 2014; Morgan et al., 2008). This limited experience and utilization may be contributing to misconceptions and unrealistic expectations and should be considered when developing strategies to address these misconceptions within a session.

\section{Genesurance discussions in practice}

Considering the fact that over $67 \%$ of respondents felt that genesurance discussions might alter their decision to pursue genetic testing, it is not surprising that a large majority of patients wish to discuss these issues prior to making a decision. Based on the survey responses, the majority of patients would like to spend up to ten minutes discussing genesurance topics during a session. This finding is consistent with the Brown et al. study in which genetic counselors report spending 8 minutes on average exploring genesurance topics in a session.

In strategizing how best to communicate information regarding health insurance, patients suggested having educational brochures or materials available for review or to takehome:

"Waiting room information, [like] brochures or ads"

"Talk about it with everyone, visual aids \& explanations are always helpful." Others suggested providing patients with CPT codes so that they could contact their insurance company: 
"Provide complete diagnosis testing codes [so] that I may contact my insurance to confirm prices for testing”

"Prompt [patients] to contact insurance company to check the genetic tests recommended. Perhaps give a checklist of things for individuals to ask of their insurance."

While this topic can seem daunting, it is important to recognize that many patients do not expect expertise in insurance-related topics, but rather guidance and support.

"Have a general idea about what is covered and what is not. Encourage patients to check with their insurance. Have informed billing staff that can answer questions and provide you with contact info to insurance company."

\section{Who is responsible for Genesurance discussions?}

Respondents indicated that the two major parties responsible for genesurance discussions are genetic counselors and the patients themselves. This indicates a willingness on behalf of the patient to be an active participant in these discussions.

"I feel it is my responsibility to check into coverage with the assistance of clinic staff that deal with billing and insurance, since there are so many types of insurance coverage out there."

Interestingly, patients felt diagnostic laboratories were least responsible for addressing genesurance topics. This finding may indicate a fundamental misunderstanding of third party payor systems and the intricacies of genetic testing. Many patients mentioned the utility of having a dedicated staff member or liaison to help patients navigate insurancerelated topics. 
"Providers and insurance never seem to be on the same page. It would ease the patient's burden if there was a liaison among providers, laboratories, insurance, and the patient."

Since this may not be a feasible option in most clinic settings, these conversations often fall to genetic counselors (Brown, 2017). It remains to be determined if genetic counselors are the most appropriate, qualified, and cost-effective individuals to have these conversations, as conversations about insurance-related topics are not currently reimbursable charges. Further research into these areas is needed.

\section{Primary-care provider differences}

Although over $80 \%$ of patients expect insurance-related topics to be addressed in a genetic counseling session, only $37 \%$ of patients expected these topics to be addressed at every visit in a primary care setting. This could demonstrate that patients have higher expectations of more specialized providers. Compared to other medical tests or procedures patients routinely encounter, "genetic testing" can have a "non-routine" connotation, which can heighten patient's anxiety, and subsequently their expectations from their providers. Additionally, this could be explained by patient's lack of familiarity with genetic counseling as a specialty, leading to uncertainty about many aspects of a genetic counseling session. Future investigation comparing patient expectations of other specialty providers (i.e. cardiologists, oncologists, etc.) to expectations of genetic counselors may elucidate whether the differences of provider expectations observed in this study are specific to genetic counseling or to all specialized medicine. 


\section{Health Insurance Literacy}

Overall, the surveyed population reported high levels of confidence and actionability on the previously validated Health Insurance Literacy Measure (HILM). In general, respondent's reported Health Insurance Literacy (HIL) did not affect patient expectations of genetic counselors in genesurance discussions. However, this measure does not address specific scenarios that may arise when dealing with third party payors, and therefore may not be an accurate measurement of HIL in the context of a genetic counseling session. Additionally, the limitations of a self-reported measure must be taken into consideration, as respondents could report higher levels of confidence or actionability than what is observed in an actual genetic counseling setting.

\section{Future Research}

This study highlights the opportunities for further research on the topic of insurancerelated discussions in a genetic counseling session. Considering the frequency of these discussions and patient's expectations to have them, future research is needed to investigate current training practices of Genetic Counseling Training Programs in insurance related topics. Additionally, development of educational materials may aid in the facilitation of these discussions. Given the limitations of the Health Insurance Literacy Measure (HILM) in the context of genetic counseling, additional research or studies into the modification of the HILM or the creation of a novel measure may assist genetic counselors in assessing patient's HIL in order to further tailor genesurance discussions. 


\section{Limitations of the Study}

This study had a few main limitations: 1) Self-reporting bias - all responses were selfreported and were based on personal opinions, perceptions, experiences, and beliefs. Responses were not confirmed or assessed by genetic counselors or other study personnel. 2) Selection bias - individuals who participated in the study likely had stronger opinions or expectations in genesurance discussions. Individuals who declined to participate in the study may have represented individuals with lower health insurance literacy or individuals who had neutral or ambivalent opinions about the discussion of genesurance topics. 3) Use of nonvalidated survey components - the survey was carefully developed to evaluate the aims of this study and was divided into subsections. The HILM was a validated tool designed to assess health insurance literacy, however the remaining subsections have not been validated in other studies. 4) Mixed study population - participants were receiving either prenatal or cancer genetic counseling where the expectation and use of testing information may be different depending on the setting.

\section{Conclusions}

There is no denying that navigating insurance-related discussions in a healthcare setting can be complex and uncomfortable. However, genetic counselors have a unique skill set designed to educate clients about complex issues, tailor information to individual needs, and promote informed decision-making. While these skills can help facilitate genesurance discussions in a genetic counseling session, it remains unclear whether these discussions should fall within the scope of practice of genetic counselors and what the best strategies are to approach this complex topic. 
In the age of personalized medicine, it is clear that patients expect and desire to have all aspects of their healthcare personalized, including conversations about insurance coverage. While genesurance discussions may pose unique challenges in a genetic counseling session they have become an integral part of our practice, indicating the need for further assessment and training in these topics. 


\section{APPENDIX A: Patient Survey}

You are invited to take part in a research study exploring topics of health insurance literacy and expectations to discuss insurance during a genetic counseling appointment. Your participation will require approximately 5-10 minutes. There are no known discomforts associated with this survey. Taking part in this survey is completely voluntary, and you may withdraw at any time. Your responses will be kept anonymous, and digital data will be stored in secure computer files after it is entered. Any report of this research that is made available to the public will not include your name or other identifiable information. Once you complete this survey, you will be eligible to enter your name and contact information in a drawing to win a $\$ 25$ Target gift cards. Completing this survey indicates that you are 18 years of age and indicates your consent to participate in the research. If you have any questions regarding this study please contact the Principal Investigator: Chelsea Wagner at Chelsea.rickman@uth.tmc.edu .

\section{Section 1 of 5}

1.) What is your age?

2.) What type of insurance do you currently have?

a. Private Insurance (ex: Aetna, Cigna, Blue Cross Blue Shield, etc.)

b. Public Insurance (ex: Medicaid, Medicare, CHIP, etc.)

c. Other:

d. I'm not sure

3.) How do you obtain health insurance?

a. Purchase yourself

b. Covered under spouse's insurance

c. Receive coverage through your job

d. Apply for coverage through government programs (ex: Medicaid, Medicare, CHIP, etc.)

e. Other:

f. I'm not sure
4.) Please specific your ethnicity:

a. White/Caucasian

b. Hispanic or Latino

c. Black or African American

d. Native American

e. Asian/Pacific Islander

f. Other:

5.) Were you born in the United States?

a. Yes

b. No (please specify where you were born):

6.) What is your annual household income?
a. Less than $\$ 24,999$
b. $\$ 25,000-\$ 49,999$
c. $\$ 50,000-\$ 100,000$
d. $\$ 100,000$ or more
e. Prefer not to answer

Section 2 of 5

The following questions are designed to learn more about what people know about health insurance and using a health insurance plan to get care. Read the following BOLD statements and place an " $X$ " in the box that corresponds to your response to the statement.

\begin{tabular}{|l|l|l|l|l|}
\hline How confident are you that...... & $\begin{array}{c}\text { Not at all } \\
\text { confident }\end{array}$ & $\begin{array}{c}\text { Slightly } \\
\text { confident }\end{array}$ & $\begin{array}{c}\text { Moderately } \\
\text { confident }\end{array}$ & $\begin{array}{c}\text { Very } \\
\text { confident }\end{array}$ \\
\hline $\begin{array}{l}\text { 1. You know how to find out what is and is not } \\
\text { covered before you receive a health care service? }\end{array}$ & & & & \\
\hline $\begin{array}{l}\text { 2. You know how to figure out your share of the } \\
\text { cost for care, after the health plan pays their } \\
\text { share? }\end{array}$ & & & & \\
\hline $\begin{array}{l}\text { 3. You know what questions to ask your health } \\
\text { plan if you have a coverage problem? }\end{array}$ & & & & \\
\hline $\begin{array}{l}\text { 4. You know what to do if your health plan } \\
\text { refuses to pay for a service you think should be } \\
\text { covered? }\end{array}$ & & & & \\
\hline
\end{tabular}




\begin{tabular}{|l|l|l|l|l|}
\hline $\begin{array}{l}\text { When using your health insurance } \\
\text { plan, how likely are you to..... }\end{array}$ & Not at all likely & Somewhat likely & $\begin{array}{c}\text { Moderately } \\
\text { likely }\end{array}$ & Very likely \\
\hline $\begin{array}{l}\text { 5. Look into what your health plan will and will } \\
\text { not cover before you get health care services? }\end{array}$ & & & & \\
\hline $\begin{array}{l}\text { 6. Look to member services to tell you what } \\
\text { medical services your health plan covers? }\end{array}$ & & & & \\
\hline $\begin{array}{l}\text { 7. Find out if a doctor is in-network before you } \\
\text { see him/her? A network is a group of doctors, } \\
\text { hospitals, and other health care professionals, } \\
\text { who have a contract with a health insurance plan } \\
\text { to take care of the plan's members. }\end{array}$ & & & & \\
\hline $\begin{array}{l}\text { 8. Review the statements you get from your } \\
\text { health plan showing what you owe and what they } \\
\text { paid for a service? }\end{array}$ & & & & \\
\hline
\end{tabular}

\section{Section 3 of 5}

Please rank your agreement on a scale of 1-5 with the following statements by circling the corresponding number. (1=strongly disagree, 2 =disagree, $3=$ =agree, $4=$ strongly agree)

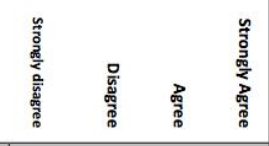

1.) My decision whether or not to pursue genetic testing may change based on discussions I may $14 \quad 2 \quad 3 \quad 4$ have about insurance coverage during my genetic counseling session.

2.) I feel responsible for asking questions regarding my specific insurance coverage of a genetic test or procedure.

3.) I want to spend time during my genetic counseling session discussing insurance coverage of genetic tests or procedures

4.) I expect my health care provider or their staff to provide me with information about my specific insurance coverage for tests and procedures I am offered

\section{Section 4 of 5}

Read the BOLD sentence and complete the statement by circling "YES" or "NO."

\section{Do you expect your genetic counselor to}

Discuss the insurance coverage of genetic tests or procedures during your appointment

Have knowledge of my personal insurance plan and coverage.

YES NO

Have knowledge if a genetic test or procedure is a covered benefit.

YES NO

Give an exact out-of-pocket cost for a genetic test or procedure.

YES NO

Give an estimated out-of-pocket cost for a genetic test or procedure.

YES NO

Provide referral or contact information for someone to answer additional

YES

NO 


\section{Section 5 of 5}

You may or may not be offered genetic testing at today's genetic counseling appointment. The insurance coverage or expected out of pocket costs for these tests or procedures may or may not be discussed by the genetic counselor.

1.) At a typical doctor's appointment do you ASK questions about your insurance coverage for tests or procedures?

a. All of the time

b. Only under certain circumstances (please specify by checking all that apply):

$\square$ Blood Work

Imaging studies (x-rays, MRI, CT scan)

CPrescriptions

Referral to specialists

$\square$ Other (please specify)

c. No

2.) At a typical doctor's appointment do you EXPECT your insurance coverage for tests or procedures to be discussed during your visit?

a. All of the time

b. Only under certain circumstances (please specify by checking all that apply):

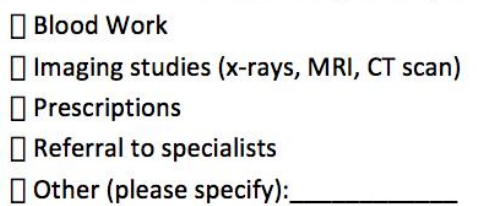

c. No

d. I had not thought about insurance coverage until taking this survey

3.) Which of the following situations would prompt you to ASK questions regarding insurance coverage in today's genetic counseling appointment?

a. If I am offered a genetic test or procedure

b. If I would have to pay any money out of pocket

c. If the amount of money I had to pay was over a certain amount (please specify):

$$
\begin{aligned}
& \text { If I had to pay over } \$ 50 \\
& \text { If I had to pay over } \$ 100 \\
& \text { If I had to pay over } \$ 200 \\
& \text { If I had to pay over } \$ 500
\end{aligned}
$$

d. If I am unsure if a test or procedure is a covered benefit

e. I would not ask questions regarding my insurance coverage

4.) In which of the following situations would you EXPECT your genetic counselor to address your insurance coverage, without you asking specific questions?

a. If I am offered any genetic test or procedure

b. If I would have to pay any money out of pocket

c. If the amount of money I had to pay was over a certain amount (please specify):

$\square$ If I had to pay over $\$ 50$

If I had to pay over $\$ 100$

If I had to pay over $\$ 200$

If I had to pay over $\$ 500$

d. If I am unsure if a test or procedure is a covered benefit

e. I would not expect my genetic counselor to address these issues 
5.) When would you like your genetic counselor to address insurance coverage and related topics?

a. Only if I bring these topics up

b. Before I make a decision about genetic testing

c. After I make a decision about genetic testing

d. Prefer that the counselor did not address this topic at all

6.) How long would you like your genetic counselor to spend discussing insurance-related topics?

a. Less than five minutes

b. Between 5-10 minutes

c. More than 10 minutes

d. Until I have no more questions

e. Prefer the counselor did not spend time addressing this topic during our session

7.) Who do you believe is responsible for discussing insurance coverage about genetic tests or procedures? (Check all that apply):

(1) My genetic counselor

My physician

(] My insurance company

(] The lab who will run the test

(1) A billing or insurance representative

Q Office or administrative support personnel

( I am responsible for asking or speaking with someone about my specific coverage

8.) Have you met with a genetic counselor before?

a. Yes

b. No (proceed to question 12 )

9.) If yes, did your genetic counselor offer any genetic tests during your appointment?

a. Yes

b. No (proceed to question 12)

10.) If yes, did your genetic counselor discuss insurance coverage of genetic tests or procedures that were offered?

a. Yes

b. No (proceed to question 12)

11.) If yes, how long (approximately) did your genetic counselor spend discussing insurance coverage?

a. Less than 5 minutes

b. Between 5-10 minutes

c. More than 10 minutes

12.) How can health providers, including genetic counselors, best help you understand your health insurance coverage information?

THANK YOU FOR YOUR PARTICIPATION 


\section{BIBLIOGRAPHY}

Alexander, G. C., Casalino, L. P., \& Meltzer, D. O. (2003). Patient-physician communication about out-of-pocket costs. JAMA, 290(7), 953-958. doi:10.1001/jama.290.7.953

Blumberg, L. J., Long, S. K., Kenney, G. M., \& Goin, D. Public understanding of basic health insurance concepts on the eve of health reform. Provider, 64(82.0), 52.54.

Brown, S. (2017). Genesurance: The mysterious element of genetic counseling. Paper presented at the National Society of Genetic Counselors Annual Education Conference, Seattle, Washington.

Long, S. K., \& Goin, D. (2014). Large racial and ethnic differences in health insurance literacy signal need for targeted education and outreach. Health, 73(12.4), 14.16.

Morgan, R. O., Teal, C. R., Hasche, J. C., Petersen, L. A., Byrne, M. M., Paterniti, D. A., \& Virnig, B. A. (2008). Does poorer familiarity with Medicare translate into worse access to health care? Journal of the American Geriatrics Society, 56(11), 2053-2060.

Paez, K. A., Mallery, C. J., Noel, H., Pugliese, C., McSorley, V. E., Lucado, J. L., \& Ganachari, D. (2014). Development of the Health Insurance Literacy Measure (HILM): Conceptualizing and measuring consumer ability to choose and use private health insurance. Journal of health communication, 19(sup2), 225-239.

Patel, M. R., \& Wheeler, J. R. (2014). Physician-patient communication on cost and affordability in asthma care. Who wants to talk about it and who is actually doing it. Annals of the American Thoracic Society, 11(10), 1538-1544.

Quincy, L. (2012). Measuring health insurance literacy: A call to action. Yonkers: Consumers Union. 
Riggs, K. R., \& Ubel, P. A. (2014). Overcoming barriers to discussing out-of-pocket costs with patients. JAMA internal medicine, 174(6), 849-850.

Ubel, P. A., Abernethy, A. P., \& Zafar, S. Y. (2013). Full disclosure--out-of-pocket costs as side effects. $N$ Engl J Med, 369(16), 1484-1486. doi:10.1056/NEJMp1306826

Zafar, S. Y., Peppercorn, J. M., Schrag, D., Taylor, D. H., Goetzinger, A. M., Zhong, X., \& Abernethy, A. P. (2013). The financial toxicity of cancer treatment: a pilot study assessing out-of-pocket expenses and the insured cancer patient's experience.

Oncologist, 18(4), 381-390. doi:10.1634/theoncologist.2012-0279 


\section{VITAE}

Chelsea Alice Wagner was born in Shawnee Mission, Kansas on November 13, 1992, to the parents of Jennifer and Ronald Magee and Rodney and Theresa Rickman. After completing her work at Platte County High School, Platte County, Missouri in 2011, she was awarded a full scholarship to Truman State University in Kirksville, Missouri. She received her Bachelor of Science with a major in Biology and minor in Disability Studies from Truman State University in May, 2015. In August of 2015, she entered The MD Anderson Cancer Center UTHealth Graduate School of Biomedical Sciences to pursue a degree in Genetic Counseling.

Permanent Address:

7490 Brompton St.

Apt. 418

Houston, TX 77025 